(NCBI). mRNA expression of distinct clones were confirmed by RT-PCR. Moreover, in situ hybridization showed that distinct genes, such as Fbx3 and S100A4, were also expressed on synovial tissues from patients with RA but not from non-RA patients, suggesting that these molecules may contribute to the pathogenesis of RA.

Conclusion In this study, a number of molecules, including several novel genes, were isolated from RA-SF using suppression subtraction hybridization. The expression of these molecules may be involved in synovial activation in the pathogenesis of RA. "K. Masuda is supported by Japan Rheumatism Foundation.

\section{OP0023 ADENO-ASSOCIATED VIRUS ENCODING FOR IL-4 INHIBITS COLLAGEN-INDUCED ARTHRITIS}

N Bessis, V Cottard, D Mulleman, MC Boissier. Immunology and Rheumatology, University of Paris 13, UPRES EA-2361, Bobigny, France

10.1136/annrheumdis-2001.948

Background Gene therapy is a promising strategy for rheumatoid arthritis. Adeno-associated virus (AAV) are recently developed vectors with unique set of characteristics like their ability to infect host cells at any time of their division cycle, and their possible weak immunogenicity in mammals. IL-4 is a Th- 2 antiinflammatory cytokine that is efficient if delivered by continuous administration in collagen-induced arthritis (CIA) in mice.

Objectives The present study was undertaken to investigate the possibility to use AAV vectors in CIA.

Methods AAV vectors, expressing lacZ (AAV-lacZ) or IL-4 (AAVIL-4) cDNA under CMV promotor control, were produced and purified by Généthon (Evry, France). DBA/1 mice were used for all studies. After i.m. injection of 2.5109 AAV-lacZ particles, lacZ expression was examined on tissue cryosection by $\mathrm{X}$-gal staining. IL-4 transgene expression was evaluated in vivo different times after i.m. injection of AAV-IL-4 by an IL-4 ELISA on muscles lysates. LacZ quantitative expression was evaluated after i.m. injections of AAV-lacZ by X-gal colorimetric assay on muscle lysates. AAV antibodies levels were measured by a neutalizing assay. CIA was induced by immunisation with bovine type II collagen. For treatment, 1.31010 AAV-IL-4 were administered i.m. to mice 11 days prior to induction of CIA.

Results Peri-articular injection of AAV-lacZ showed an expression of the transgene localised in the deep muscles cells near the bone. IL-4 in vivo expression was detected at least 120 days after AAV-IL-4 injection i.m. Anti-AAV neutralising antibodies were detected in the serum after AAV-lacZ administration in vivo, but they didn't altered the transgene expression after readministration of AAV-lacZ. CIA mice treated with AAV-IL-4 were significantly improved in comparisation to control, in terms of prevalence of the disease, arthritis scores, and histological evaluation. Locally, a slight inflammation at the point of vector injection was noted.

Conclusion AAV is a powerful vector for gene therapy in CIA. AAV IL-4 prevent the development of CIA. In addition, our data are consistent with a long term persistance of the transgene and the possibility of a readministration.
OP0061 RECOMBINANT OSTEOPROTEGERIN (OPG) REGULATES BONE EROSIONS AND OSTEOCLAST NUMBERS IN A SCHEDULE-DEPENDENT MANNER IN JOINTS OF MALE LEWIS RATS WITH ADJUVANT ARTHRITIS

U Feige, G Campagnuolo, B Bolon. Pharmacology/Pathology, Amgen, Thousand Oaks, USA

10.1136/annrheumdis-2001.949

Background Our laboratory has shown that bone destruction in the Lewis rat model of adjuvant arthritis (AdA) can be significantly reduced by daily administration of recombinant human osteoprotegerin (rhOPG) if treatment is initiated at the onset of clinical arthritis. ${ }^{1}$

Objectives The current study was performed to assess the ability of rhOPG to spare bone using an abbreviated dosing schedule.

Methods AdA was induced in male Lewis rats $(8$ weeks old, $\mathrm{n}=$ 6/group) on Day 0; clinical arthritis (indicated by hind paw swelling) developed on Day 9. Arthritic animals received rhOPG (daily s.c. bolus of $4 \mathrm{mg} / \mathrm{kg}$ ) by one of four schedules: no rhOPG (Group 1, control for AdA induction); daily rHOPG, Days 9 to 15 (Group 2, control for rhOPG efficacy); early intervention, Days 9 to 11 (Group 3); or delayed intervention, Days 13 to 15 (Group 4). Rats were necropsied on Day 16, and bone mineral density [BMD] of bones in the tibiotarsal (ankle) joint was measured by DEXA (dual X-ray absorptiometry). Next, sections of formalin-fixed, decalcified, paraffin-embedded hind paws were stained by an indirect immunohistochemical method to detect cathepsin K, an osteoclast marker. Histopathologic scores to assess lesion severity (given below as group means \pm standard deviation) were acquired for inflammation, bone erosion, and osteoclast numbers using tiered, semi-quantitative grading scales. Results Joints of vehicle-treated arthritic animals (Group 1) exhibited measurable loss of BMD as well as extensive inflammation $(4.0 \pm 0)$, skeletal erosion $(4.5 \pm 0.5)$, and osteoclast production $(4.0 \pm 0)$. As noted previously, ${ }^{2}$ rhOPG therapy throughout the 7-day clinical course of AdA (Group 2) preserved BMD and almost completely inhibited erosions $(1.2 \pm 0.4)$ and osteoclastogenesis $(0.8 \pm 0.8)$ but did not modify the extent of inflammation $(3.7 \pm 0.5)$. Early initiation of rhOPG treatment (Group 3) yielded similar retention of BMD as well as reductions in erosion $(1.2 \pm 0.4)$ and osteoclast $(1.7 \pm 0.5)$ scores. However, in comparison to Groups 2 and 3, delayed rhOPG administration (Group 4) protected BMD and lowered the mean osteoclast score $(2.0 \pm 0.3)$ but was significantly less effective in preventing erosions $(2.5 \pm 1.4)$.

Conclusion Our data indicate that early intervention with a bone-sparing agent such as rhOPG is needed to obtain the greatest clinical benefit with respect to protecting skeletal integrity in arthritic joints but also show that delayed rhOPG therapy can reduce the loss of joint $\mathrm{BMD}$ even in the presence of severe inflammation.

\section{REFERENCES}

1 Kong, et al. Nature 1999;402:304

2 Feige, et al. Ann Rheum Dis. 2000;59(Suppl I):148

\section{THU0073 ELASTASE AND LACTOFERRIN AS INDICATORS OF FUNCTIONAL ACTIVITY OF POLYMORPHONUCLEAR CELLS IN RHEUMATOID ARTHRITIS}

TG Danilova, AV Danilov, NI Korshunov, LA Tsyganova, EV Riazantseva, IM Borodulina. Internal Diseases, Yaroslavl State Medical Academy, Yaroslavl, Russia

10.1136/annrheumdis-2001.950 
Background The role of polymorphonuclear cells in the development of a chronic inflammatory process still remains controversial. Neutrophilic granules comprise various biologically active proteins, which play a pathogenic role in the development of chronic auto-immune diseases, such as rheumatoid arthritis. Elastase - a marker of primary granules, being a factor of protection in healthy individuals, may exert a pro-inflammatory effect in rheumatoid arthritis, promoting the degradation of the cartilage matrix and the activation of proteolytic enzymes. The constituent of secondary neutrophilic granules - lactoferrin - a $77 \mathrm{kDa}$ protein with certain anti-microbal and anti-inflammatory properties.

Objectives To evaluate the role of constituents of neutrophilic granules ? lactoferrin and elastase ? in the pathogenesis of rheumatoid arthritis.

Methods In this study the serum levels of elastase and lactoferrin and an immunohistochemical staining reaction of polymorphonuclear cells for lactoferrin were assessed in 70 patients with rheumatoid arthritis.

Results The serum level of elastase - a marker of neutrophils' activation - was dramatically increased in patients with rheumatoid arthritis in comparison to healthy persons ( $p<0.001$ ). However, the serum level of lactoferrin was significantly decreased in patients with rheumatoid arthritis (195.5 \pm 11.7 $\mathrm{ng} / \mathrm{ml}$ vs. $626.9 \pm 20.8 \mathrm{ng} / \mathrm{ml}$ in healthy donors; $\mathrm{p}<0.001)$. Blood neutrophils displayed weak staining for lactoferrin in rheumatoid arthritis. The decrease of serum level of lactoferrin and its concentration in polymorphonuclear cells was greater in patients who were diagnosed with extra-articular manifestations, such as rheumatoid nodules and Felty's syndrome $(\mathrm{p}<0.05)$. These patients also had greater serum level of elastase. The serum level of lactoferrin didn't depend on the presence or absence of a rheumatoid factor or on the intensity of radiographic changes, but it inversely correlated with the serum levels of elastase, IgA, IgG, C-reactive protein and erythrocyte sedimentation rate. Treatment with non-steroidal anti-inflammatory drugs resulted in a clinical amelioration and was accompanied by the decrease of serum elastase level $(\mathrm{p}<0.01)$. The serum level of lactoferrin was slightly raised after treatment $(\mathrm{p}<0.05)$, which we consider to be a secondary effect due to decreased lactoferrin consumption. However, the intensity of neutrophilic staining reaction for lactoferrin remained unchanged.

Conclusion These data suggest a dysfunction of polymorphonuclear cells in rheumatoid arthritis: active synthesis and secretion of elastase is accompanied by the decreased synthesis of lactoferrin. The deficiency of lactoferrin - a potent antioxidant - may contribute to disease activity and the development of extra-articular manifestation in rheumatoid arthritis. The mechanism of this deficiency still remains unclear.

\section{THU0074 VITAMIN E UNCOUPLES JOINT INFLAMMATION AND ARTICULAR DESTRUCTION, IN A TRANSGENIC MOUSE MODEL OF RHEUMATOID ARTHRITIS}

${ }^{1} \mathrm{MJ}$ De Bandt, ${ }^{1} \mathrm{~F}$ Driss, ${ }^{1} \mathrm{M}$ Grossin, ${ }^{2} \mathrm{~J}$ Pincemail, ${ }^{1} \mathrm{C}$ Babin-Chevaye, ${ }^{3} \mathrm{C}$ Gaertner, ${ }^{1} \mathrm{C}$ Pasquier. IINSERM U 479, Bichat, Paris, France; ${ }^{2} \mathrm{CHU}$ de Liège, Domaine Du Start Tilman, Liège, Belgique; ${ }^{3}$ COGNIS, Dusseldorf, Deutschland

\subsection{6/annrheumdis-2001.951}

Background Reactive oxygen species (ROS) are suspected to play a role in human RA. Transient hypoxia and ischaemic-reperfusion phenomenon are involved in their chronic production, by monocytes and macrophages. Nevertheless the clinical interest of ROS scavengers is difficult to evaluate.

Objectives

Methods We studied the effects of Vitamin E (natural alpha tocopherol) on transgenic KRN/NOD mice, new model for rheumatoid arthritis. We determined clinical, histological and biochemical parameters so as to define the long-term benefit of Vitamin E in the disease.

Results We found an increase in plasma Vit E, in treated mice. Vitamin $\mathrm{E}$ treatment did not modify the date of onset of the disease, neither the intensity of the disease (arthritic index and weight), but Vit-E prevented from articular destruction, suggesting uncoupling of the two phenomenon. Biochemical analysis, blood glutathion, urine isoprostane and the plasma hydroperoxide did not differ between Vit E-treated transgenic KRN/NOD mice and control mice. Blood chemiluminescence was increased in transgenic KRN/NOD mice as compared to non-transgenic mice, and was decreased in Vit E-treated transgenic KRN/NOD mice. TNF-a and IL1-b, low in control non-transgenic mice, were increased in transgenic KRN/NOD mice, however a significant decreased in IL-1b appeared in Vit E-treated mice.

Conclusion These results suggest that ROS scavengers can modulate cytokines responses and provide new arguments for the interest of ROS scavengers in RA therapy.

\section{THU0075 MYCOPLASMA PNEUMONIAE INFECTION AND RHEUMATOID ARTHRITIS}

AS Ramirez-Corbera, JA Hernández-Beriain, A Rosas, E Girona. Rheumatology Section, Hospital Insular de GC, Las Palmas de GC, Spain

10.1136/annrheumdis-2001.952

Background An infective aetiology for rheumatoid arthritis (RA) has often been postulated. Thirteen species of mycoplasmas has been implicated in the origin of arthritis in experimental models and animals. Fragments of mycoplasma (PCR) has been detected in RA although the results are conflictive.

Objectives The main of our work is to evaluate previous mycoplasma pneumoniae (MP) infection in a cohort of RA outpatients and further evaluation of MP infection and RA outcome.

Methods In 80 RA patients IgG antiMP was evaluated with ELISA. RA was evaluated according to disease duration, RF status and radiological stage. In control group were included 150 healthy people. Statistical analysis included Kruskal-Wallis test for IgG levels and determination of relative risk (odds ratio).

Results Mean age of RA patients was 53.17 (22-81 years); 83\% were females. MP serology was positive in 54\% of RA patients and $31 \%$ of controls $(\mathrm{p}<0.05)$. Medium level of IgG was 1.431 in RA patients and 0.87 in controls $(\mathrm{p}<0.0001)$. Previous MP infection conditioned a relative risk (odds ratio) for RA of 3.22 (95 CI; 1.76-5.91).

Conclusion Previous MP infection was more frequent in RA patients than controls. MP infection could play a role in RA genesis. 